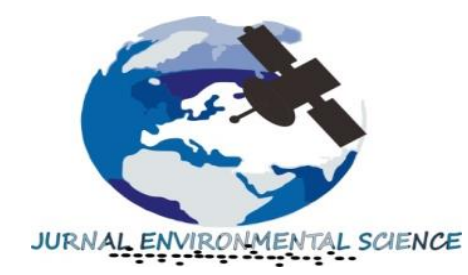

Jurnal EnvironmentaI Science

Volume 1 Nomor 1 Oktober 2018.

p-ISSN : 2654-4490 dan e-ISSN : 2654-9085

Homepage at : ojs.unm.ac.id/JES

E-mail:jes@unm.ac.id

\title{
REPRESENTASI ATURAN ADAT DALAM PENGELOLAAN HUTAN MASYARAKAT ADAT AMMATOA SULAWESI SELATAN
}

\author{
Erman Syarif \\ Jurusan Geografi, Fakultas Matematika dan Ilmu Pengetahuan Alam, \\ Universitas Negeri Makassar, 2018, Indonesia
}

\begin{abstract}
Pasang is the customary rule of the Ammatoa community in forest management. The objectives of this study are: 1) to identify the role of forests (boronga) for the Ammatoa's people, (2) to identify customary rules in the management of Ammatoa's peoples forests. This type of research is qualitative using a phenomenology approach. The data sources in this study were Ammatoa (adat chief), Galla Puto (adat leader), Galla Pantama (adat leader), Ammatoa's peoples and cultural figures. Data collection is done by observation, interviews, Focus Group Discussion and documentation. Data verification strategy with data triangulation, member checks, and audit trail. The results of the study show that the Ammatoa's people in managing forest resources are inseparable from their belief in tide teachings. Forest management is strengthened by the existence of Kasipalli (prohibitions) that should not be carried out in the forest area, namely Ta'bang Kaju (logging), Rao Doang (taking shrimp), Tatta 'Uhe (taking rattan), and Tunu Bani (burning bees). Each of these violations is always accompanied by customary sanctions. Customary sanctions given to forest destroyers who have been identified and captured by the community are divided into 3 parts, namely: Poko babbalak (pangkal cambuk), tangnga babbalak (middle whip), and cappa babbalak (tip of the whip). As for the unknown perpetrators, the Ammatoa performed Attunu Panroli (burning crowbar) and Attunu Passau (burning kemenyang) ceremonies. This form of sanction is a deterrent effect so that the community truly understands the importance of implementing the Pasang and use of forest areas.
\end{abstract}

Keywords: Customary rules; Forest management; and Ammatoa's peoples

\begin{abstract}
ABSTRAK
Pasang merupakan aturan adat masyarakat Ammatoa dalam pengelolaan hutan. Tujuan penelitian ini yaitu: 1) mengidentifikasi peranan hutan (boronga) bagi masyarakat adat Ammatoa, (2) mengidentifikasi aturan adat dalam pengelolaan hutan masyarakat adat Ammatoa. Jenis penelitian ini adalah kualitatif dengan menggunakan pendekatan fenomenologi. Sumber data dalam penelitian ini yakni Ammatoa (Kepala adat), Galla Puto (Pemangku adat), Galla Pantama (Pemangku adat), Masyarakat adat Ammatoa, dan Budayawan. Pengumpulan data dilakukan dengan observasi, wawancara, Focus Group Discussion dan dokumentasi. Strategi verifikasi data dengan triangulasi data, member chek, dan audit trail. Hasil penelitian menunjukkan bahwa masyarakat adat Ammatoa dalam mengelola sumber daya hutan tidak terlepas dari kepercayaannya terhadap ajaran Pasang. Pengelolaan hutan diperkuat dari adanya Kasipalli (larangan) yang tidak boleh dilakukan dalam kawasan hutan yaitu Ta'bang Kaju (menebang kayu), Rao Doang (mengambil udang), Tatta' Uhe (mengambil rotan), dan Tunu Bani (membakar lebah). Setiap pelanggaran tersebut selalu diiringi sanksi adat. Sanksi adat yang diberikan kepada pelaku perusak hutan yang sudah diketahui identitasnya dan ditangkap oleh
\end{abstract}


masyarakat terbagi menjadi 3 bagian yaitu: pokok babbalak (pangkal cambuk), tangnga babbalak (tengah cambuk), dan cappa babbalak (ujung cambuk). Sedangkan bagi pelaku yang tidak diketahui identitasnya, maka Ammatoa melakukan upacara Attunu Panroli (pembakaran linggis) dan Attunu Passau (pembakaran kemenyang). Bentuk pemberian sanksi tersebut merupakan efek jera agar masyarakat betul-betul paham arti pentingnya mengamalkan Pasang dan pemanfaatan kawasan hutan.

Kata Kunci: Aturan adat, Pengelolaan hutan, dan Masyarakat adat Ammatoa

\section{PENDAHULUAN}

Budaya tidak dapat dipisahkan dari kehidupan masyarakat. Soemarwono (2001) kebudayaan merupakan suatu kebiasaan yang telah tertanam lama dan terbentuk dari nilai dan norma yang telah dianut dan diwariskan secara turun temurun dalam sebuah kelompok masyarakat sejak kelahiran nenek moyang mereka. Dalam kebudayaan juga tercakup aspek yang selalu menjadi penopang kehidupan manusia seperti, agama, budi pekerti, bahasa, keluarga, ekonomi, politik, alat-alat teknologi, gaya hidup, dan lain-lain. Lebih lanjut Geertz (1992) manusia dan budaya adaah satu kesatuan yang tidak bisa dipisahkan antara satu sama lain. Maka dari itu, kebudayaan tidak pernah dapat dipisahkan dari masyarakat karena merupakan hal esensial yang telah melekat dan selalu berjalan seiring dengan peradaban manusia (Syarif, 2016).

Kerusakan hutan yang terjadi di Indonesia mengalami peningkatan yang tinggi. Kementerian Kehutanan (2015) luas kawasan hutan Indonesia mencapai 120 juta ha. Luasan hutan ini sudah mengalami degradasi dan deforestasi sehingga luas yang tersisa sebenarnya hanya sekitar 75\% atau 90 juta ha. Forest Wacth Indonesia (2015) secara keseluruhan Indonesia telah kehilangan lebih dari $72 \%$ dari wilayah hutan alam utuhnya dan $40 \%$ dari tutupan hutannya sama sekali hancur. Mengamati kerusakan hutan yang terjadi, aksi untuk mempertahankan eksistensi hutan merupakan hal mendesak. Hal ini disebabkan hutan sebagai salah satu penyangga penting bagi kehidupan umat manusia dengan berbagai fungsinya.

Arti penting pemanfaatan kawasan hutan bagi masyarakat adat Ammatoa. Ibrahim (2001) hutan perlu dijaga keutuhan dan dilestarikannya karena hutan bernilai historis yang mengingatkan mereka tentang asal usul dan kebesaran leluhur mereka di masa lalu. Syarif (2017) bagi masyarakat adat Ammatoa diyakini bahwa merawat hutan merupakan bagian dari ajaran Pasang, karena hutan memiliki kekuatan gaib yang dapat mensejahterakan dan sekaligus mendatangkan bencana manakala tidak dijaga kelestariannya. 
Pasang merupakan aturan adat masyarakat adat Ammatoa dalam pemanfaatan dan pengelolaan hutan. Adhan (2005) masyarakat adat Ammatoa tumbuh dan berkembang dengan Pasang sebagai aturan/ketentuan dari tindakan mereka. Lebih lanjut Akib (2003) Pasang berisi aturan ketentuan serta hukuman yang harus dipatuhi oleh masyarakat adat. Pasang berisi nilai-nilai, prinsip-prinsip, hukum dan aturan dalam merajut hubungan manusia dengan Tuhan, hubungan antar sesama manusia, dan hubungan manusia dengan alam semesta (Lureng, 1991). Masyarakat adat Ammatoa dalam mengelola sumber daya hutan tidak terlepas dari kepercayaannya terhadap ajaran Pasang (Syarif, 2016).

Berdasarkan latar belakang tersebut, maka riset ini mengkaji: (1) mengidentifikasi peranan hutan (boronga) bagi masyarakat adat Ammatoa, (2) mengidentifikasi aturan adat dalam pengelolaan hutan masyarakat adat Ammatoa.

\section{METODE PENELITIAN}

Jenis penelitian ini adalah kualitatif dengan menggunakan pendekatan fenomenologi. Lokasi penelitian di Desa Tana Towa Kec. Kajang Kab. Bulukumba Sulawesi Selatan.

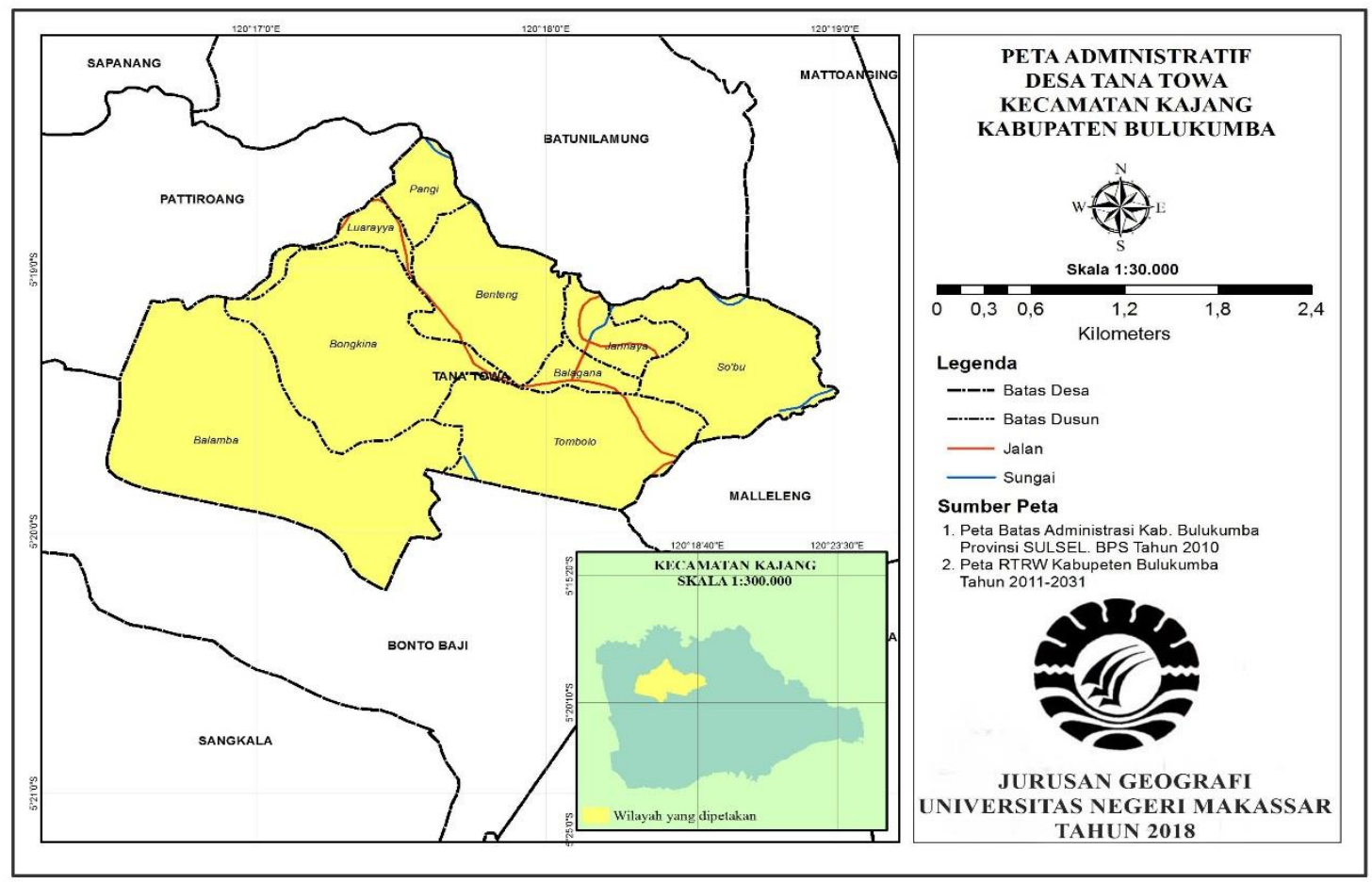

Gambar 1: Peta Administratif Desa Tana Towa Kecamatan Kajang Kabupaten Bulukumba 
Taksonomi Informan dapat dilihat pada tabel 1.1 berikut:

Tabel. 1.1 Taksonomi Informan

\begin{tabular}{|c|c|c|}
\hline \multirow{4}{*}{ Informan } & Informan Kunci & Informan Pendukung \\
\hline & 1) Ammatoa (Kepala adat) & 1) Masyarakat adat Ammatoa \\
\hline & 2) Galla Puto (Pemangku adat) & 2) Budayawan \\
\hline & 3) Galla Pantama (Pemangku adat) & \\
\hline
\end{tabular}

Pertanyaan yang diajukan kepada Informan dapat dilihat pada tabel 1.2 berikut:

\section{Tabel 1.2 Pertanyaan yang di ajukan kepada Informan}

\begin{tabular}{lll}
\hline No & \multicolumn{1}{c}{ Pertanyaan Struktural } & \multicolumn{1}{c}{ Informan } \\
\hline 1 & Peranan hutan & Galla Pantama, Budayawan, dan Masyarakat adat. \\
2 & Aturan adat & Ammatoa, Galla Puto, dan Budayawan \\
\hline
\end{tabular}

Pengumpulan data melalui observasi, wawancara, dan dokumentasi. Strategi verifikasi data dengan triangulasi data, member chek, dan audit trail.

\section{HASIL DAN PEMBAHASAN}

\section{Tabel 1.3 Matriks Informasi yang diperoleh dari Informan}

\begin{tabular}{|c|c|c|c|}
\hline No. & Informan & Informasi yang diberikan & Domain yang ditemukan \\
\hline 1 & $\begin{array}{l}\text { Galla Pantama } \\
\text { (pemangku adat) }\end{array}$ & $\begin{array}{l}\text { Rupa tauwa siangang bonena linoa parallui nikatutui } \\
\text { na natallasiki. Rupa tauwa parallui nikatutui bonena } \\
\text { linoa, contona nikatutui boronga siagang olo-oloka, } \\
\text { wasselena nikanre,nibalukang wasselena boronga, } \\
\text { kajunna di pareki balla pammantangang siagang } \\
\text { sanna inja pa'matu matuanna mange ri rupa tauwa, } \\
\text { niami ilalanna kanyamangang siangang akkatuhoi } \\
\text { timbusu } \\
\text { Artinya: } \\
\text { Manusia dan alam saling menunjang dan saling } \\
\text { menghidupi. Manusia memelihara alam, misalnya } \\
\text { memelihara hutan dan satwa yang ada di dalamnya, } \\
\text { hasilnya dimakan, dikomersialkan hasil hutannya, } \\
\text { kayunya dibuat rumah tinggal dan masih banyak } \\
\text { manfaat lainnya bagi manusia, termasuk kesejukan } \\
\text { serta mempertahankan sumber mata air. }\end{array}$ & $\begin{array}{l}\text { Arti penting keberadaan } \\
\text { hutan bagi masyarakat adat } \\
\text { Ammatoa }\end{array}$ \\
\hline 2 & $\begin{array}{l}\text { Mansyur Emba } \\
\text { (Budayawan) }\end{array}$ & $\begin{array}{l}\text { Masyarakat yang hidup dalam kawasan rambanga } \\
\text { bohe Amma (dalam kawasan adat Ammatoa) sangat } \\
\text { memegang teguh perinsip pasang ri kajang, khususnya } \\
\text { pelestarian hutan sebab: 1) boronga appariyeki } \\
\text { katalassang (hutan mendatangkan sumber kehidupan), } \\
\text { 2) boronga akkatuhoi timbusu (hutan menjaga } \\
\text { ketersediaan sumber mata air, 3) boronga appambani } i \\
\text { bosi (hutan mendatangkan hujan), dan 4) boronga } \\
\text { appadingingi pakrasangang (hutan menyejukkan } \\
\text { lingkungan) }\end{array}$ & $\begin{array}{l}\text { Arti penting keberadaan } \\
\text { hutan bagi masyarakat adat } \\
\text { Ammatoa }\end{array}$ \\
\hline
\end{tabular}


$3 \quad$ Massaninga (masyarakat adat Ammatoa)

4

Galla Puto (Pemangku adat)

Mansyur Emba (Budayawan) (Kepala Adat)
Tau ada'a ri kajang iya mintu nikau Ammatoa natappa, apparakai borong natappa saba battu ripangngara pasang, nasaba ia injo borongnga riek pangissenganna nukkulle appakahaji katalassang, akkullei to'i pakriek kakodiang punna anrek nijagai kelestarianna. Iya mintu parallu nipiarah boronga supaya lere-lerei balaiya nukkulea natora katallasanna rupa taua.

Artinya:

Masyarakat adat Ammatoa meyakini, merawat hutan merupakan bagian dari ajaran Pasang, karena hutan memiliki kekuatan gaib yang dapat mensejahterakan, sekaligus mendatangkan bencana manakala tidak dijaga kelestariannya. Untuk itu mereka senantiasa memelihara hutan agar terhindar dari mara bahaya yang dapat mengancam kehidupan mereka.

Ammatoa Anjo Atoranna ada'ka punna nia palanggarang ri boronga ta'bagei tallu iamintu: pokok babbalak, tangnga babbalak siagang cappa babbalak.

Artinya:

Sanksi adat ketika terjadi pelanggaran di dalam kawasan hutan terbagi menjadi 3 bagian yaitu: pokok babbalak (pangkal cambuk), tangnga babbalak (tengah cambuk), dan cappa babbalak (ujung cambuk).

Atoranna adaka punna nia amparaki boronga nakana atorranna Pasanga ri kajang iamiantu Pokok Babbala, Tangnga Babbala, siagang Cappa Babbala. Atorang kamma anjo punna niissengi tau ampangrakiyai anjo boronga.

Artinya:

Sanksi bagi perusak hutan menurut Pasang ri kajang adalah pelanggaran berat (Pokok Babbala), pelanggaran sedang (Tangnga Babbala), dan pelanggaran ringan (Cappa Babbala). Sanksi ini diberikan kepada pelaku perusak hutan yang sudah diketahui identitasnya dan ditangkap oleh masyarakat. Sedangkan bagi pelaku yang tidak diketahui identitasnya, ada sejenis hukuman yang sering dilakukan oleh masyarakat Ammatoa, yang disebut Attunu Panroli (bakar Linggis) dan Attunu Passau (pembakaran kemenyang).

Prinsip hidup sederhana yang merupakan implementasi dari nilai-nilai Pasang, juga terdapat aturan-aturan pemanfaatan hutan yang juga berasal dari Pasang. Aturan-aturan ini secara jelas mengatur masyarakat adat Ammatoa dalam mengelola hutan. Aturan itu pun lengkap dengan sanksi yang jelas dan tegas di dalamnya. Dan masyarakatnya pun patuh terhadap aturan-aturan itu hingga hari ini.

Sumber: Hasil Penelitian, 2018

\section{Peranan Hutan (Boronga) bagi Masyarakat Adat Ammatoa}

Merawat hutan bagi masyarakat adat Ammatoa merupakan bagian dari ajaran Pasang, karena hutan merupakan bagian dari tanah yang diberikan oleh Tu Rie A' ra'na (Tuhan Yang 
Maha Esa) kepada leluhur masyarakat adat Ammatoa. Mereka meyakini bahwa di dalam hutan terdapat kekuatan gaib yang dapat mensejahterahkan dan sekaligus mendatangkan bencana ketika hutan tersebut tidak dijaga kelestariannya. Kekuatan tersebut menurut mereka berasal dari arwah leluhur masyarakat kajang yang senantiasa menjaga kelestarian hutan agar terbebas dari niat-niat jahat manusia (Ahmad, 1991). Jika ada orang yang berani merusak kawasan hutan, misalnya menebang pohon dan membunuh hewan yang ada di dalamnya, maka arwah para leluhur tersebut menurunkan kutukan. Kutukan tersebut dapat berupa penyakit yang diderita oleh orang yang bersangkutan, atau juga mengakibatkan berhentinya air yang mengalir di lingkungan Desa Tana Towa (Adhan, 2005).

Masyarakat adat Ammatoa mempunyai pandangan bahwa hutan merupakan bagian dari struktur kepercayaan mereka. Menurut Pasang (pesan atau petuah yang hariis dipatuhi), hutan keramat menyimpan nilai historis atas kehadiran To Manurung (Ammatoa pertama). Adanya kepercayaan bahwa To Manurung atau Ammatoa pertama turun dari langit di suatu puncak berbentuk tombolo (tempurung) yang dikelilingi air dengan seekor burung yang disebut Koajang. Menurut kepercayaan mereka juga, Ammatoa pertama tersebut kembali ke langit dengan cara sajang (menghilang) di dalam Borong Karamaka (hutan keramat).

Masyarakat adat Ammatoa dalam mengelola sumber daya hutan tidak terlepas dari kepercayaannya terhadap ajaran Pasang. Masyarakat adat Ammatoa memahami bahwa dunia yang diciptakan oleh Tu Rie A' ra'na beserta isinya haruslah dijaga keseimbangannya, terutama hutan. Karenanya hutan harus dipelihara dengan baik dan mendapat perlakuan khusus bagi penghuninya serta tidak boleh merusaknya. Salah satu Pasang berbunyi: "Anjo boronga anre nakkulle nipanraki. Punna nipanraki boronga, nupanraki kalennu" artinya hutan tidak boleh dirusak. Jika engkau merusaknya, maka sama halnya engkau merusak dirimu sendiri. Selain itu, Pasang lain berbunyi: "Anjo natahang ri boronga karana pasang. Rettopi tanayya rettoi ada" artinya hutan bisa lestari karena dijaga oleh adat. Bila bumi hancur, maka hancur pula adat.

Kawasan hutan sebagai tempat masyarakat adat Ammatoa menggantungkan hidup. Menurut Iskandar (2013) masyarakat lokal adalah penduduk yang masih memegang atau memilki tradisi secara turun temurun dari generasi ke generasi berikutnya dalam kurun waktu yang sangat lama, tinggal dan berinteraksi dengan lingkungannya secara terus menerus. Dalam hal ini, masyarakat adat Ammatoa mengelola hutannya didasarkan pada adat istiadat dan dikelola secara sungguh-sungguh tanpa merusaknya. Karena mereka menganggap bahwa mengelola hutan sama saja menyayangi dunia. Apabila ada masyarakat yang merusaknya maka sanksi adat berlaku padanya sebagai ganjaran di dunia karena berlaku kasar pada alam. 
Masyarakat adat Ammatoa meyakini bahwa hutan memiliki kekuatan gaib, selain itu Pasang telah mengajarkan mereka untuk menjaga hutan.

Fungsi hutan bagi masyarakat adat Ammatoa yaitu (1) fungsi ritual, yaitu bagian dari sistem kepercayaan, yang memandang hutan (borong karamaka) sebagai suatu tempat upacara. Berbagai upacara yang dilakukan dalam hutan yakni pelantikan Ammatoa, Attunu Passau (upacara kutukan bagi pelanggar adat), upacara pelepasan nazar, dan upacara apparuntuk paknganro (bermohon kepada Tu Rie A' ra'na untuk suatu hajat baik individual maupun kolektif), dan (2) fungsi ekologis, yaitu sebagai pengatur tata air. Apparik e bosi dan apparik e tumbusuk artinya menyebabkan turunnya hujan dan timbulnya mata air (wawancara Galla Puto, tanggal 23 April 2016). Lebih lanjut Akib (2003) mengungkapkan hutan harus dilestarikan karena merupakan bagian utama dari agama dan ritual pada masyarakat adat Ammatoa di Kajang. Larangan yang tidak boleh dilakukan masyarakat adat Ammatoa dalam kawasan hutan yaitu Ta'bang Kaju (menebang kayu), Rao Doang (mengambil udang), Tatta' Uhe (mengambil rotan), dan Tunu Bani (membakar lebah).

Keyakinan inilah yang menyebabkan kuatnya keterkaitan antara masyarakat Ammatoa dengan hutan, sehingga hutan tetap lestari. Sebagaimana dikemukakan Ahmad (1991) bahwa komunitas Ammatoa mengganggap ekosistem hutan sebagai bagian dari struktur kepercayaan mereka, yaitu sebagai tangga untuk turun naiknya arwah manusia ke bumi dan ke langit, sebagai tempat turunnya manusia pertama (Tutowa Mariolo, Mula Tau atau Ammatoa), dan sebagai bumi yang pertama kali diciptakan oleh Tu Rie A' ra'na (Tuhan Yang Maha Esa). Ajaran Patuntung mengajarkan jika manusia ingin mendapatkan sumber kebenaran, maka ia harus menyandarkan diri pada tiga pilar utama, yaitu menghormati Tu Rie A' ra'na, tanah yang diberikan Tu Rie A' ra'na, dan nenek moyang (Adhan, 2005).

\section{Aturan Adat dalam Pengelolaan Hutan Masyarakat Adat Ammatoa}

Kaedah Hukum adat dalam mengelola hutan masyarakat adat Ammatoa meliputi:

\section{a) Asas atau Prinsip}

Masyarakat adat Ammatoa menganut prinsip/asas dalam mengelola hutan, seperti: prinsip hormat terhadap alam, prinsip tanggung jawab terhadap alam, prinsip solidaritas kosmis, prinsip kasih sayang dan kepedulian terhadap alam, prinsip hidup sederhana, prinsip hidup selaras dengan alam dan prinsip keadilan.

b) Nilai

Nilai yang berlaku dalam masyarakat adat Ammatoa dalam mengelola hutan adalah bersumber dari ajaran Pasang, yakni: lambusu' (kejujuran), gattang (ketegasan), sa 'bara 
(kesabaran), apiso'na (kepasrahan). Nilai-nilai tersebut bersumber dari prinsip hidup Kamase-mase, yaitu prinsip mengutamakan kehidupan miskin di dunia, agar memperoleh imbalan kekayaan dari Tuhan di hari kemudian.

\section{c) Aturan Adat}

Pantangan atau Kasipalli dalam ajaran Pasang dikenakan sanksi-sanksi adat ketika dilangggar yakni:

1. Babbala (cambuk), terbagi atas tiga tingkatan, yaitu:

a) Pokok babbalak

Tindakan pelanggaran berat (Pokok babbalak/pangkal cambuk) dihukum denda sebesar Rp. 800.000, ditambah satu gulung kain putih. Pencurian atau pelanggaran adat lainnya yang dilakukan di dalam Borong Karamaka (hutan keramat) digolongkan sebagai pelanggaran berat.

b) Tangnga babbalak

Pelanggaran sedang (Tangnga babbalak/tengah cambuk) dihukum denda sebesar Rp. 400.000, ditambah dengan kain putih satu gulung. Pencurian atau pelanggaran adat lainnya yang dilakukan di dalam Borong Batassayya (hutan perbatasan) dikategorikan sebagai pelanggaran sedang.

c) Cappa babbalak

Pelanggaran ringan (Cappa babbalak/ujung cambuk) dihukum denda sebesar Rp. 200.000, ditambah dengan satu gulung kain putih. Pencurian atau pelanggaran adat lainnya yang dilakukan di dalam Borong Luarayya (hutan rakyat) oleh masyarakat dikategorikan sebagai pelangggaran ringan.

2. Attunu Panroli (pembakaran Lingkis)

Apabila pelaku pelangaran tidak mengakuinya/tidak diketahui, maka atas inisiatif dari Ammatoa sebagai kepala adat melakukan upacara Attunu Panroli untuk mengungkap kebenaran. Upacara Attunu Panroli untuk mengetahui siapa yang jujur di antara masyarakat adat Ammatoa. Apabila linggis yang dibakar telah merah menyala, yang memimpin upacara tersebut memperlihatkan kepada hadirin bahwa yang memegang linggis tersebut tidak terbakar jika memang ia benar. Sesudah itu, Ammatoa bersama perangkat adat lainnya memerintahkan kepada semua yang hadir untuk memegang linggis yang memerah karena panas. Siapa diantara mereka yang benar dan jujur, pasti mereka tidak merasakan panasnya 
linggis tersebut. Sebaliknya siapa yang curang, tidak jujur, maka mereka pasti terbakar. Dengan cara itu, orang yang melakukan pelanggaran akan mengakui kesalahannya.

3. Attunu Passau (pembakaran kemenyang)

Apabila pelaku pelanggaran tidak hadir pada saat upacara Attunu Panroli karena ingin menghindari hukuman atau ingin melarikan diri ke daerah lain, maka Ammatoa bersama pemangku adat lainnya melakukan upacara pembakaran passau/kemenyang (Attunu Passau). Passau diambil dari sarang lebah, disimpan di rumah Ammatoa selama 5 hari sebelum dibakar untuk didinginkan dan diberi mantra-mantra. Passau tersebut dibakar ditempat terjadinya pelanggaran dan berlaku selama tiga bulan sejak Passau dibakar. Masyarakat adat Ammatoa meyakini bahwa selama Passau masih ditiup oleh angin, maka sipelanggar pasti tidak dapat menghindar walaupun bersembunyi di langit ataupun ke perut bumi. Pelaku yang dikenakan Passau akan memperoleh sanksi yang sakral seperti perut membengkak, terjangkit penyakit kusta, nipa' loha (lupa ingatan), yang tidak dapat sembuh hingga mengalami kematian.

Kearifan lokal merupakan pandangan dan pengetahuan tradisional yang menjadi acuan dalam berperilaku dan telah dipraktekkan secara turun-temurun untuk memenuhi kebutuhan dan tantangan dalam kehidupan suatu masyarakat. Susilo (2008) mengungkapkan bahwa penting untuk melembagakan kembali kearifan-kearifan lokal tradisional, karena membantu penyelamatan lingkungan. Kearifan lokal berfungsi dan bermakna dalam masyarakat baik dalam pelestarian sumber daya alam dan manusia, mempertahankan adat dan budaya, serta bermanfaat untuk kehidupan (Permana, 2011).

Hukum adat memiliki potensi untuk mengelola dan melindungi hutan secara lestari. Ibrahim (2001) pengelolaan sumber daya hutan oleh masyarakat masyarakat adat Ammatoa di Kajang bersumber pada ajaran Pasang ri Kajang yang berfungsi untuk menjaga dan melindungi kawasan hutan. Pengelolaan hutan harus disesuaikan dengan potensi hutan dan kondisi sosial budaya masyarakat setempat (Simon, 1994). Sistem budaya lokal merupakan modal sosial (social capital) yang besar, telah tumbuh-berkembang secara turun-temurun yang hingga kini kuat berurat-berakar di masyarakat (Hikmat, 2010). Praktek pengelolaan hutan masyarakat adat Ammatoa di Kajang mempraktekkan pengelolaan hutan secara lestari. 


\section{SIMPULAN}

Nilai-nilai ajaran Pasang yang dimiliki masyarakat adat Ammatoa sarat dengan kearifan lokal yang di dalamnya terkandung filosofi keselarasan, keharmonisan, dan rasionalitas dari tindakan masyarakat dengan lingkungannya. Merawat hutan bagi masyarakat adat Ammatoa merupakan bagian dari ajaran Pasang. Ammatoa sangat tegas dalam memberikan sanksi adat ketika terdapat pelanggaran yang dilakukan oleh masyarakat, karena tindakan tersebut sudah termasuk menyalahi Pasang. Bentuk pemberian sanksi tersebut merupakan efek jera agar masyarakat betul-betul paham arti pentingnya mengamalkan Pasang dan menghargai lingkungan alam (hutan).

\section{SARAN}

1. Pelestarian hutan di kawasan adat Ammatoa, senantiasa dilandasi prinsip Tallasa kamase-mase (kesederhanaan) dan ajaran Pasang sebagai suatu nilai yang dipegang erat. Melestarikan hutan merupakan bagian dari ajaran Pasang, karena hutan memiliki kekuatan gaib yang dapat mensejahterakan, sekaligus mendatangkan bencana manakala tidak dijaga kelestariannya. Oleh karena itu, peranan Ammatoa terhadap pelestarian lingkungan alam (hutan), memegang peranan penting untuk terus menerus memelihara, mempertahankan dan melestarikan lingkungan alam termasuk hutan, kemudian didukung oleh segenap warga masyarakatnya. Bentuk upaya ini diharapkan dapat terus dilakukan dalam rangka mengantarkan segenap warga masyarakat untuk hidup sejahtera, berkecukupan, bahkan kaya dengan melalui prinsip Tallasa kamasemase.

2. Masyarakat adat Ammatoa harus berpegang teguh pada ketentuan aturan adat yang bersumber pada Pasang, dan mentaati peraturan yang berasal dari pemerintah, sehingga dengan ketaatan itu diharapkan kesejahteraan mereka dapat lebih ditingkatkan melalui tuntunan dan program pemerintah.

\section{DAFTAR RUJUKAN}

Adhan. 2005. Sistem Nilai Masyarakat Ammatoa. Makassar: Pustaka Refleksi.

Ahmad. S. 1991. Pendidikan dan Sistem Kepercayaan Adat Ammatoa. Makassar: Pustaka Refleksi.

Akib. Y. 2003. Potret Manusia Kajang. Makassar: Pustaka Refleksi. 
Syarif, E., Sumarmi, S., Fatchan, A., \& Astina, I. K. 2016. Integrasi Nilai Budaya Etnis Bugis Makassar Dalam Proses Pembelajaran Sebagai Salah Satu Strategi Menghadapi Era Masyarakat Ekonomi Asean (MEA). Jurnal Teori dan Praksis Pembelajaran IPS, 1(1), 13-21.

Syarif, E., Hasriyanti, H., Fatchan, A., Astina, I. K., \& Sumarmi, S. (2016). Conservation Values Of Local Wisdom Traditional Ceremony Rambu Solo Toraja's Tribe South Sulawesi As Efforts The Establishment Of Character Education. EFL JOURNAL, 1(1), $17-23$.

Syarif, E., Fatchan, A., \& Astina, K. 2016. Tradition of" Pasang Ri-Kajang" in the Forests Managing in System Mores of" Ammatoa" at District Bulukumba South Sulawesi, Indonesia. Mediterranean Journal of Social Sciences, 7(6), 325.

Syarif, E. 2017. Studi Fenomenologi Makna Pasang ri Kajang dalam Pengelolaan Hutan Masyarakat Adat Ammatoa Bulukumba Sulawesi Selatan. DISERTASI dan TESIS Program Pascasarjana UM.

Syarif, E. 2017. Environmental Management in Local Wisdom Perspective of Karampuang People, Sinjai District, South Sulawesi. Sainsmat, 6(2).

Forest Watch Indonesia. 2015. Potret Keadaan Hutan Indonesia Periode 2010-2015. Bogor: Forest Watch Indonesia.

Geertz, C. 1992. Kebudayaan dan Agama. Terjemahan Yogyakarta: Konisius

Hikmat, Harry. 2010. Strategi Pemberdayaan Masyarakat. Bandung: Humaniora Utama Press.

Ibrahim. 2001. Kelembagaan dan Sistem Pelestarian Sumberdaya Hutan di Desa Tana Towa Sulawesi Selatan. Yogyakarta: Pustaka Pelajar.

Iskandar (2013) Iskandar. J. 2013. Ekologi Manusia dan Pembangunan Berkelanjutan. Bandung: Remaja Rosdakarya.

Kementerian Kehutanan. 2015. Kebijakan Pengelolaan Hutan. Jakarta

Lureng, Gaffar. 1980. Pasang ri Kajang: Suatu Pendekatan Dari Segi Antropologi. Disertasi tidak dipublikasikan. Makassar: Program Pascasarjana Universitas Hasanuddin.

Simon, H. 1994. Merencanakan Pembangunan Hutan untuk Strategi Kehutanan Sosial. Yogyakarta: Aditya Media.

Susilo, Rahmat. 2008. Kearifan Tradisional Masyarakat dan Pembangunan Berkelanjutan. Yogyakarta: Transmedia Global Wacana. 
Permana, C. E., Nasution, I. P., \& Gunawijaya, J. 2011. Kearifan Lokal Tentang Mitigasi Bencana Pada Masyarakat Baduy. Jurnal. Jurusan Arkeologi Fakultas Ilmu Pengetahuan Budaya. Jakarta: Universitas Indonesia.

Ramli. 2012. Manusia dan kebudayaan Masyarakat Kajang. Makassar: Pustaka Refleksi.

Soemarwoto. 2001. Teori Kebudayaan dan Manusia. Bandung: Mizan. 